\title{
Neural Correlates of Pavlovian Conditioning in Components of the Neural Network Supporting Ciliary Locomotion in Hermissenda
}

\author{
Terry Crow ${ }^{1}$ and Lian-Ming Tian \\ Department of Neurobiology and Anatomy, University of Texas Medical School, Houston, Texas 77030
}

\begin{abstract}
Pavlovian conditioning in Hermissenda consists of pairing light, the conditioned stimulus (CS) with activation of statocyst hair cells, the unconditioned stimulus (US). Conditioning produces CS-elicited foot shortening and inhibition of light-elicited locomotion, the two conditioned responses (CRs). Conditioning correlates have been identified in the primary sensory neurons (photoreceptors) of the CS pathway, interneurons that receive monosynaptic input from identified photoreceptors, and putative pedal motor neurons. While cellular mechanisms of acquisition produced by the synaptic interaction between the CS and US pathways are well-documented, little is known about the mechanisms responsible for the generation or expression of the CR. Here we show that in conditioned animals light reduced tonic firing of ciliary activating pedal neurons (VP1) below their pre-CS baseline levels. In contrast, pseudorandom controls expressed a significant increase in CS-elicited tonic firing of VP1 as compared to pre-CS baseline activity. Identified interneurons in the visual pathway that have established polysynaptic connections with VP1 were examined in conditioned animals and pseudorandom controls. Depolarization of identified type $I_{e}$ interneurons with extrinsic current elicited a significant increase in IPSPs recorded in VP1 pedal neurons of conditioned animals as compared with pseudorandom controls. Conditioning also enhanced intrinsic excitability of type $I_{e}$ interneurons of conditioned animals as compared to pseudorandom controls. Light evoked a modest increase in IPSP frequency in VP1 of conditioned preparations and a significant decrease in IPSP frequency in VP1 of pseudorandom controls. Our results show that a combination of synaptic facilitation and intrinsic enhanced excitability in identified components of the CS pathway may explain light-elicited inhibition of locomotion in conditioned animals.
\end{abstract}

Pavlovian conditioning in Hermissenda results in conditioned stimulus (CS)-elicited inhibition of phototaxis (Crow and Alkon 1978; Crow and Offenbach 1983) and CS-elicited foot contraction (Lederhendler et al. 1986). While these two motor acts appear dissimilar, inhibition of CS-elicited ciliary locomotion and CS-elicited foot contraction may synergistically interact to contribute to the inhibition of phototactic behavior observed in conditioned animals. While some progress has been made in the identification of foot contraction motor neurons (Goh and Alkon 1984) and cellular neurophysiological correlates of conditioning in a contractile pedal motor neuron (Goh et al. 1985), little is known regarding cellular plasticity in the neural network supporting ciliary locomotion in conditioned Hermissenda. Recently, pedal neurons activating cilia on the anterior foot have been identified and synaptic connections between type I, II, and III interneurons and VP1 ciliary activating pedal neurons have been established (Crow and Tian 2003).

In this report we show that Pavlovian conditioning results in light-elicited inhibition of the spike activity of VP1 pedal neurons as compared to pseudorandom controls.

${ }^{1}$ Corresponding author.

EMAIL terry.crow@uth.tmc.edu.

Article and publication are at http://www.learnmem.org/cgi/doi/ $10.1101 / 1 \mathrm{~m} .58603$.
Light elicited an increase in tonic spike activity of pseudorandom controls that was similar to light-evoked increases in tonic spike activity detected in normal untrained animals. In addition, light elicited an increase in IPSP frequency in VP1 pedal neurons of conditioned preparations, and IPSP frequency in VP1 pedal neurons evoked by depolarization of identified type $I_{e}$ interneurons was significantly increased in conditioned animals as compared to pseudorandom controls. Conditioning also produced an enhancement of intrinsic excitability of type $I_{e}$ interneurons. The previously reported facilitation of the amplitude of monosynaptic and complex EPSPs in type $\mathrm{I}_{\mathrm{e}}$ interneurons of conditioned animals in conjunction with the intrinsic enhanced excitability of type $\mathrm{I}_{\mathrm{e}}$ interneurons detected following conditioning contributes to the inhibition of ciliary locomotion elicited by light. The diversity of polysensory interneuronal synaptic projections to the motor network supporting ciliary locomotion and foot movement may explain how Pavlovian conditioning can modify components of a circuit that must also support normal visual influences of motor behavior.

\section{RESULTS}

A total of 100 animals were used in the behavioral experiments. The conditioned group consisted of 50 animals, and 50 animals served in the pseudorandom control groups.

LEARNING \& MEMORY 10:209-216 @ 2003 by Cold Spring Harbor Laboratory Press ISSN1072-0502/03 \$5.00

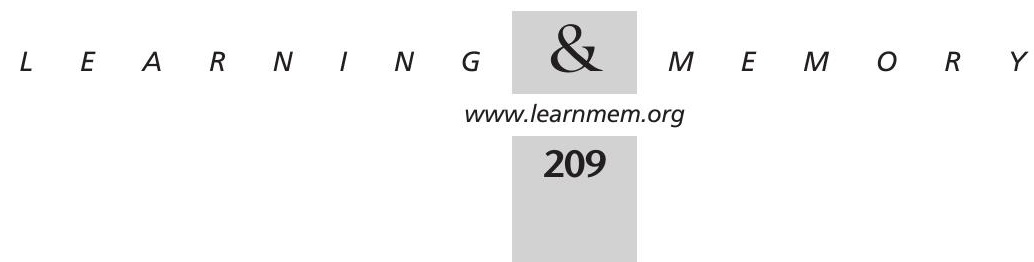


Animals were tested $24 \mathrm{~h}$ postconditioning followed by isolation of the circumesophageal nervous system and collection of electrophysiological data from type I interneurons and VP1 pedal neurons. Since not all isolated nervous systems resulted in the identification and successful penetration of interneurons and pedal neurons, the sample sizes for the neural correlates were smaller than the total number of animals included in the conditioned and pseudorandom control groups. However, the suppression ratios for these groups were not significantly different from the larger groups.

The mean suppression ratios for the conditioned and pseudorandom control groups are shown in Figure 1. As consistent with previous reports, the results of the statistical analysis showed that conditioning produced significant behavioral suppression $(\overline{\mathrm{X}}=0.30 \pm 0.03)$ as compared with the pseudorandom control group $(\overline{\mathrm{X}}=0.47 \pm 0.04)$ $\left(t_{98}=3.9 ; P<.001\right)$.

A diagram depicting components of the CS pathway projecting to ciliary activating motor neurons is shown in Figure 2 . The diagram represents identified connections between a photoreceptor and motor neurons supporting ciliary locomotion. For studies of the motor system in conditioned animals, we first examined changes in the tonic spike activity of VP1 pedal neurons during a $5 \mathrm{~min}$ period of illumination of the eyes. Activity was expressed as difference scores where a 5 min period of baseline spike activity in the dark that immediately preceded the 5 min light step was subtracted from tonic spike activity evoked in light. Examples of intracellular recordings of spike activity in VP1 during the light from a conditioned preparation and pseudorandom control are shown in Figure 3A,B. Summary group data depicting mean difference scores for the conditioned group and pseudorandom controls is shown in Figure 3C. The results showed that light elicited an increase in the tonic spike activity recorded in VP1 for the pseudorandom control group. In contrast, the spike activity of VP1 showed a decrease below baseline during the light for the

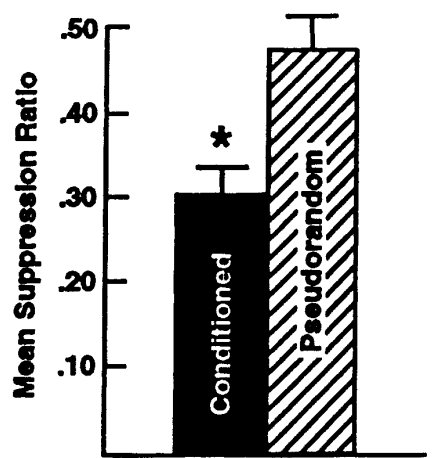

Figure 1 Mean suppression ratios \pm SEM for conditioned $(n=50)$ and pseudorandom controls $(n=50)$. Conditioning produced statistically significant suppression of light-elicited locomotion compared with pseudorandom controls $(* \mathrm{P}<0.001)$.

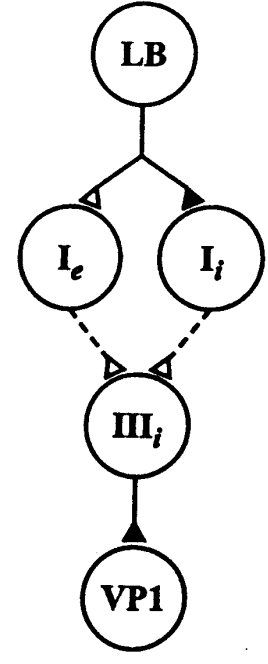

Figure 2 Components of the CS pathway involved in visually mediated ciliary locomotion in Hermissenda. Only connections with a single photoreceptor are shown. The diagram shows a monosynaptic connection between a lateral B-photoreceptor and type $I_{e}$ and $I_{i}$ interneurons. The dashed lines between the type $I_{e}$ and $\mathrm{I}_{\mathrm{i}}$ and type $\mathrm{III}_{\mathrm{i}}$ interneurons indicate a polysynaptic pathway with unidentified interneurons. The monosynaptic connections between type $\mathrm{III}_{\mathrm{i}}$ interneurons and VP1 have been previously established (Crow and Tian 2003). Filled triangles denoted inhibitory synapses, open excitatory.

conditioned group (Fig. 3A). A comparison of the difference scores shown in Fig. 3C for the conditioned group $(n=10)$ and pseudorandom controls $(n=9)$ showed that they were statistically significant $\left(t_{17}=2.1 ; P<.05\right)$. These results show that light inhibits the tonic spike activity of VP1 pedal neurons in conditioned animals.

Previous work has shown that VP1 receives polysynaptic input from components of the visual system, identified type $I_{e}$ interneurons. We examined the source of the inhibition of VP1 by recording simultaneously from type $I_{e}$ interneurons and pedal neuron VP1. As shown in the examples of Figure 4, depolarization of a type $I_{e}$ interneuron in a conditioned animal with a $2 \mathrm{sec} 0.3 \mathrm{nA}$ extrinsic current pulse evoked more IPSPs recorded in VP1 (Fig. 4A2) as compared to the example from a pseudorandom control (Fig. 4B2). The group data summarized in Figure 4C showed that mean evoked IPSP frequency relative to baseline IPSP activity was greater in VP1 pedal neurons of conditioned animals $(n=12)(\bar{X}=1.8 \pm .26)$ as compared to the pseudorandom controls $(n=9)(\bar{X}=1.2 \pm .05)$. The difference in current evoked IPSP frequency between the conditioned and pseudorandom controls was statistically significant $\left(t_{19}=1.97 ; \mathrm{p}<.05\right)$. Since the depolarizing current pulse elicited more spikes in type $I_{e}$ interneurons from conditioned preparations, the increase in the number of IPSPs evoked by stimulation of type $I_{e}$ interneurons from conditioned preparations could be due to intrinsic changes in excitability of type $I_{e}$ interneurons. We examined the excit-

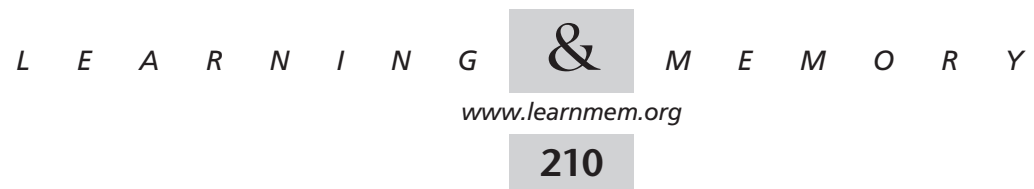



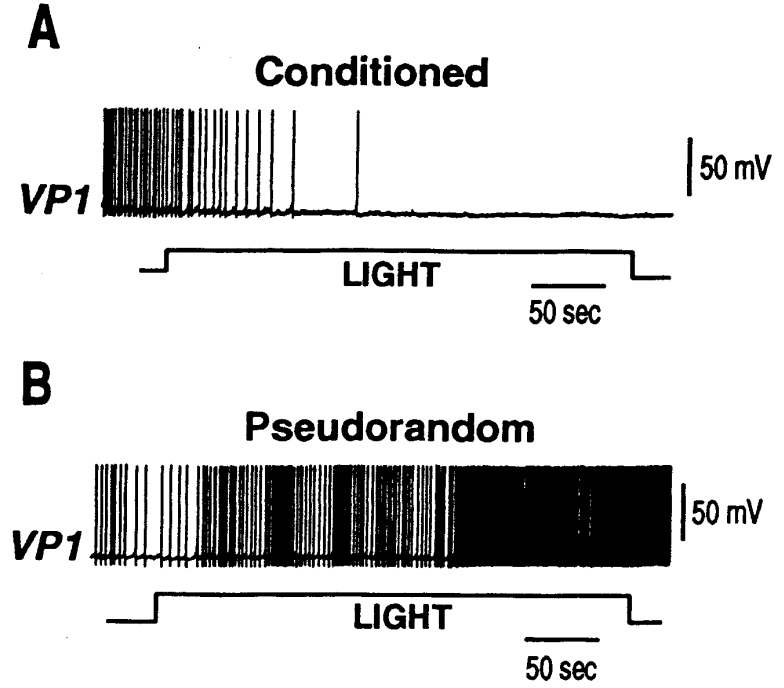

C

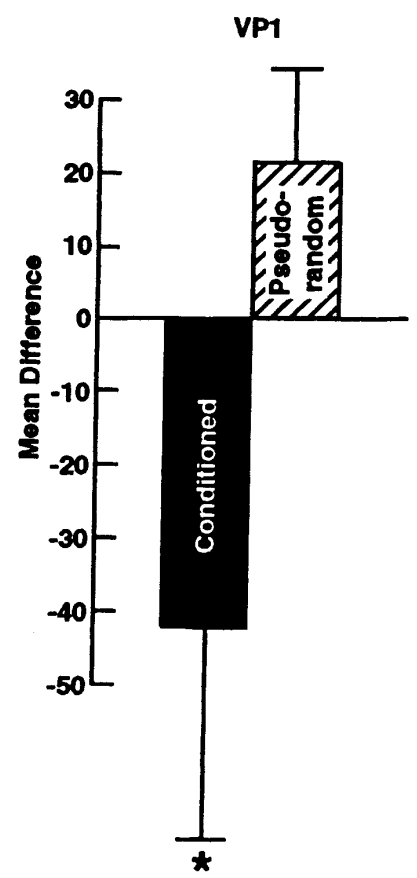

Figure 3 Examples of light-elicited changes in spike activity for conditioned animals and pseudorandom controls. (A) Light-elicited decrease in the spike activity recorded in pedal neuron VP1 from a conditioned animal. (B) Light-elicited increase in the spike activity recorded in VP1 from a pseudorandom control. (C) Group data depicting the mean difference in VP1 spike activity evoked in 5 min of light and a 5-min period in the dark immediately preceding light onset collected from conditioned animals $((n=10)$ and pseudorandom controls $(n=9 ; * P<.05)$.

ability of type $I_{e}$ interneurons further with three levels (0.1, $0.2,0.3 \mathrm{nA}$ ) of extrinsic depolarization current pulses. The examples in Figure 5A1,B1 show CS-elicited increases in spike activity in identified type $\mathrm{I}_{\mathrm{e}}$ interneurons from a conditioned preparation and a pseudorandom control. As shown previously (Crow and Tian 2002b) the CS elicits more spikes in type $\mathrm{I}_{\mathrm{e}}$ interneurons of conditioned animals. In addition, as shown in the examples in Figure 5A2-A4, type $I_{e}$ interneurons of conditioned preparations $(n=10)$ expressed more action potentials evoked by the three extrinsic current pulses of increasing magnitude as compared to pseudorandom controls (Fig. $5 \mathrm{~B} 2-\mathrm{B} 4 ; \mathrm{n}=12$ ). The analysis of the group data shown in Figure $5 \mathrm{C}$ revealed that the three levels of extrinsic current pulses evoked significantly more spikes in conditioned preparations as compared with the pseudorandom controls. The outcome of the ANOVA revealed an overall significant difference between the conditioned group and the pseudorandom controls $\left(\mathrm{F}_{1,20}=7.8\right.$; $P<.01)$. The overall effect of current levels for both groups was also statistically significant $\left(\mathrm{F}_{2,140}=151.3 ; P<.001\right)$. The interaction between the different treatments and current level was not statistically significant $\left(F_{2,20}=.41 ; \mathrm{NS}\right)$. The results showed that excitability was enhanced at all current levels for the conditioned group relative to the pseudorandom controls $(\mathrm{q}=5.9, \mathrm{q}=5.5, \mathrm{q}=5.2 ; P<.05)$. These results indicate that one contribution to the current evoked increase in IPSP frequency detected in VP1 pedal neurons, produced by depolarization of type $\mathrm{I}_{\mathrm{e}}$ interneurons, is the intrinsic enhanced excitability of type $I_{e}$ interneurons of conditioned animals.

We next examined the effect of light on the synaptic activity of VP1 pedal neurons by measuring IPSP frequency during a $1 \mathrm{~min}$ period of illumination. A $1 \mathrm{~min}$ period of spontaneous IPSPs recorded from VP1 in the dark was used to establish a baseline and changes in IPSP frequency during light were expressed as a percent of baseline IPSP activity. Examples of VP1 IPSPs occurring during light for a conditioned preparation and a pseudorandom control are shown in Figure 6A,B. Light elicited a modest increase in IPSP frequency for the conditioned preparation and a typical decrease in IPSP frequency for the pseudorandom control. The group data comparing the mean percent of baseline for IPSPs elicited during the light step for conditioned $(\bar{X}=1.09)(n=12)$ and pseudorandom controls $(\bar{X}=.84)$ $(n=11)$ is shown in Figure 6C. The statistical analysis showed that the conditioned group was significantly different from the pseudorandom controls $\left(t_{21}=3.7 ; \mathrm{p}<.001\right)$. These results show that light elicits a disinhibition of VP1 pedal neurons in pseudorandom controls as compared to the conditioned group. We have shown previously that a characteristic of the synaptic activity of VP1 is a relatively high occurrence of spontaneous IPSPs in the dark that are decreased by light (Crow and Tian 2003). Moreover, it has been shown previously that light-evoked disinhibition of VP1 is due in part to the light evoked complex IPSP detected in type $\mathrm{I}_{\mathrm{i}}$ and $\mathrm{II}_{\mathrm{i}}$ interneurons, and light-evoked excitation of type $\mathrm{II}_{\mathrm{e}}$ interneurons (Crow and Tian 2003). Our results support the hypothesis that enhanced disinhibition of VP1 mediated by the increased amplitude of complex

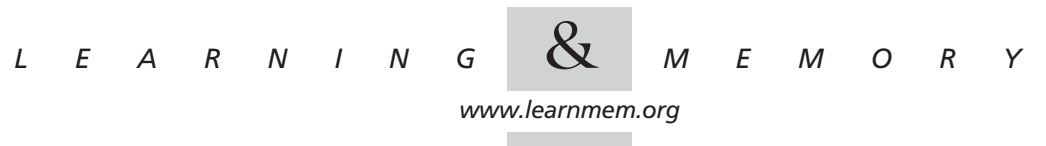


A1
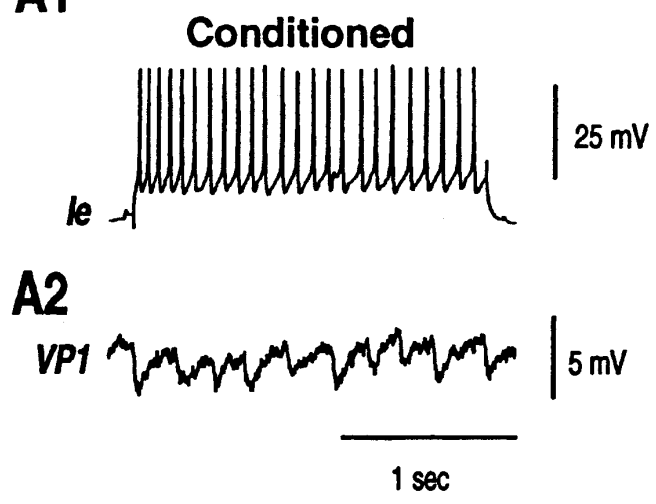

B1
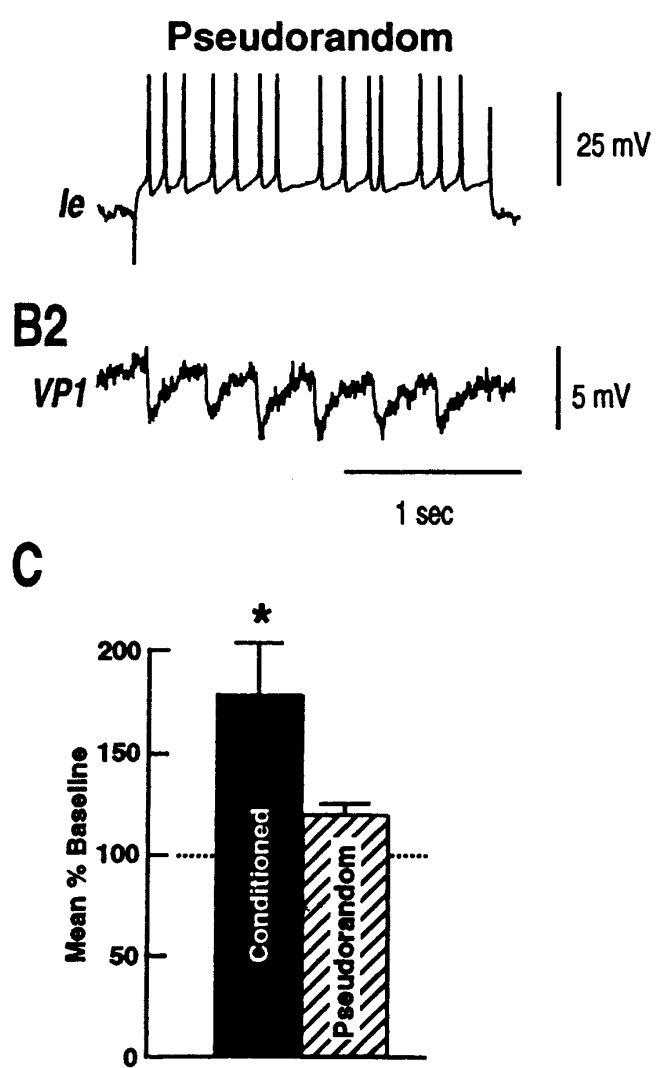

Figure 4 Examples of depolarizing current elicited IPSPs in VP1 for conditioned animals and pseudorandom controls. (A1) An example from a conditioned animal of spikes evoked by a 2 sec 0.3 $n A$ depolarizing current pulse applied to an identified type $I_{e}$ interneuron. (A2) An increase in the number of IPSPs relative to baseline recorded in VP1 elicited by depolarization of $\mathrm{I}_{\mathrm{e}}$. (B1) An example from a pseudorandom control animal of spikes evoked by a 2 sec $0.3 \mathrm{nA}$ depolarizing current pulse applied to an identified type $I_{\mathrm{e}}$ interneuron. (B2) IPSPs in VP1 evoked by depolarization of $\mathrm{I}_{\mathrm{e}}$ from a pseudorandom control. (C) Group data depicting the mean percent increase from baseline in VP1 IPSPs elicited by depolarization of identified type $\mathrm{I}_{\mathrm{e}}$ interneurons from conditioned animals $(n=12)$ and pseudorandom controls $(n=9 ; * P<.05)$.
IPSPs in type $\mathrm{I}_{\mathrm{i}}$ and $\mathrm{II}_{\mathrm{i}}$ interneurons produced by conditioning is blocked by the increased inhibition of VP1 produced by intrinsic enhanced excitability of type $I_{e}$ interneurons and synaptic facilitation of type $\mathrm{I}_{\mathrm{e}}$ monosynaptic EPSPs. Recordings from normal control preparations revealed that light typically produced a $15 \%-20 \%$ decrease in IPSP frequency in VP1 pedal neurons (Crow and Tian 2003). Therefore, light-evoked disinhibition of VP1 neurons is one mechanism for activating ciliary locomotion in Hermissenda. The results presented in this report indicate that conditioning produces an enhancement of light-evoked inhibition of VP1 ciliary activating pedal neurons.

\section{DISCUSSION}

We have examined changes in light-elicited spike activity and IPSP frequency of ciliary activating pedal neurons, and assessed changes in intrinsic excitability of type $\mathrm{I}_{\mathrm{e}}$ interneurons in classically conditioned Hermissenda. In conditioned preparations, light resulted in a significant decrease below baseline in spike activity of pedal neurons VP1. In contrast, light elicited an increase in spike activity of VP1 pedal neurons in pseudorandom controls. Previous research has shown that pedal nerves $\mathrm{P} 1$ and $\mathrm{P} 2$ contain the axons of pedal neurons responsible for generating locomotion in Hermissenda (Richards and Farley 1987). The anterior region of the foot is innervated by pedal nerve P2 (Richards and Farley 1987; Crow and Tian 2003). Intracellular recordings from VP1 neurons in conjunction with suction electrode recordings from nerve $\mathrm{P} 2$ have verified that VP1 neurons project axonal processes in pedal nerve $\mathrm{P} 2$ (Crow and Tian 2003). Our results showing that light evokes a decrease in VP1 spike activity below baseline are consistent with the previously published observations showing that conditioning reduced light-elicited extracellular spike activity recorded from pedal nerves $\mathrm{P} 1$ and $\mathrm{P} 2$, and a random control procedure produced light-elicited increases in extracellular spike activity of pedal nerves P1 and P2 (Richards and Farley 1987).

The visual and statocyst pathways are well-characterized in Hermissenda (Alkon and Fuortes 1972; Alkon 1973a,b; Alkon et al. 1978; Crow et al. 1979). Previous studies have made some progress in the identification of light-responsive putative motor neurons in the pedal ganglia (Jerussi and Alkon 1981; Goh and Alkon 1984; Goh et al. 1985; Richards and Farley 1987; Hodgson and Crow 1991; 1992). Components of the neural circuit responsible for generating ciliary locomotion in Hermissenda have now been identified (Crow and Tian 2000; 2003; see Fig. 2). Pedal neuron VP1 has been shown to activate cilia on the sole of the anterior foot (Crow and Tian 2003). We have shown that light stimulation of the visual system has two effects upon the activity of pedal neuron VP1 that is mediated by several pathways. First, light inhibits type $\mathrm{I}_{i}$ and $\mathrm{II}_{\mathrm{i}}$ interneurons, which results in disinhibition of VP1 pedal

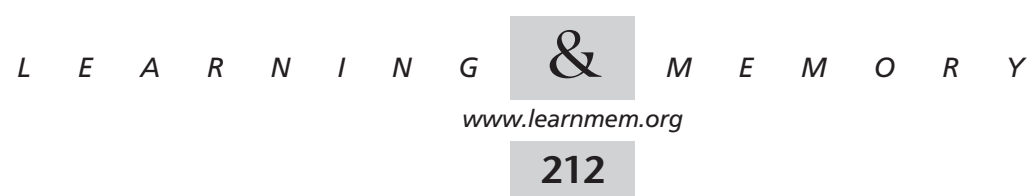


A1

B1

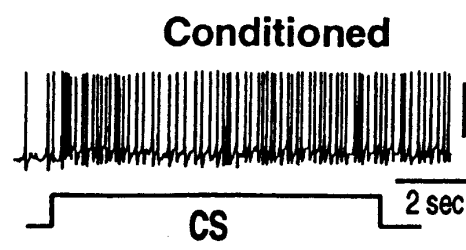

A2

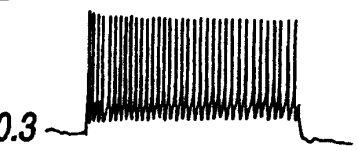

A3

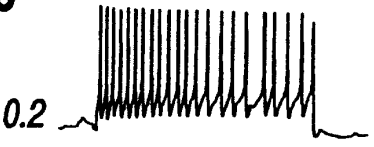

A4

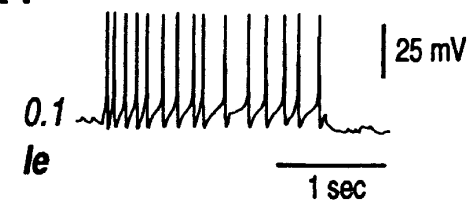

B4

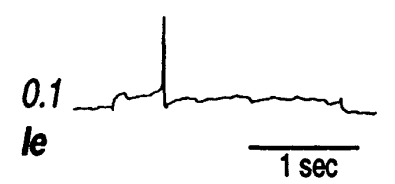

C

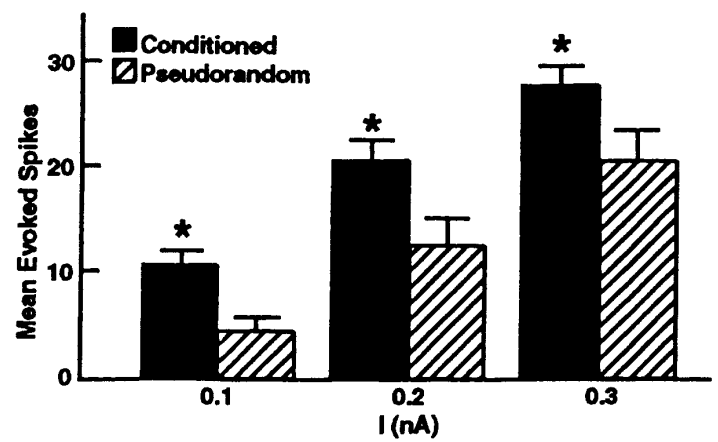

Figure 5 Conditioning produces enhanced excitability of identified type $\mathrm{I}_{\mathrm{e}}$ interneurons as compared to pseudorandom controls. (A1) An example of the CS-elicited depolarization and increase in spike frequency recorded in a type $\mathrm{I}_{\mathrm{e}}$ interneuron from a conditioned animal and a pseudorandom control (B1). (A2-A4) Excitability was assessed in the type $\mathrm{I}_{\mathrm{e}}$ interneuron shown in $(A 1)$ from a conditioned animal with 2-sec depolarizing extrinsic current pulses of increasing intensity $(0.1 \mathrm{nA}-0.3 \mathrm{nA})$. (B2-B4) Excitability of the type $\mathrm{I}_{\mathrm{e}}$ interneuron shown in (B1) from a pseudorandom control assessed with 2-sec depolarizing extrinsic current pulse of increasing intensity $(0.1 \mathrm{nA}-0.3 \mathrm{nA})$. (C) Group data showing the mean evoked spikes recorded in type $\mathrm{I}_{\mathrm{e}}$ interneurons from conditioned animals $(\mathrm{n}=10)$ and pseudorandom controls $(n=12)$ for the three different depolarizing current levels $(* P<.05)$. neurons. Second, light-elicited depolarization of type $\mathrm{II}_{e}$ interneurons also disinhibits VP1 neurons. VP1 pedal neurons receive monosynaptic inhibitory input from type III $_{i}$ interneurons. Type III $_{i}$ interneurons are inhibited by type $\mathrm{II}_{\mathrm{e}}$ interneurons and excited by type $\mathrm{I}_{\mathrm{i}}$ and $\mathrm{II}_{\mathrm{i}}$ interneurons. Therefore, light-elicited increases in tonic spike activity of VP1 pedal neurons is modulated by inhibition of type $\mathrm{I}_{\mathrm{i}}$ and $\mathrm{II}_{\mathrm{i}}$ interneurons, which results in a decrease in VP1 IPSPs generated by type III $_{i}$ interneurons. Consistent with the proposed circuitry generating ciliary locomotion and its modulation by light, we found that conditioning produced an increase in light-elicited IPSPs in VP1 pedal neurons. In contrast, lightelicited disinhibition of VP1 was observed in pseudorandom controls. Interestingly, stimulation of identified type $I_{e}$ interneurons with depolarizing extrinsic current produced a significant increase in IPSP frequency above baseline in VP1 of conditioned animals as compared with pseudorandom controls. The increase in VP1 IPSP frequency produced by depolarization of type $\mathrm{I}_{e}$ interneurons can be explained in part by the enhanced excitability of type $I_{e}$ interneurons of conditioned animals. We previously reported that conditioning produced a CS-elicited increase in spike activity of type $\mathrm{I}_{\mathrm{e}}$ interneurons (Crow and Tian 2002b). Therefore, the CS-elicited increase in type $I_{e}$ interneuron spike activity is the result of both increased synaptic facilitation of the synaptic connections between photoreceptors and type $\mathrm{I}_{\mathrm{e}}$ interneurons, CS-elicited increased spike activity of photoreceptors, and enhanced intrinsic excitability of type $I_{e}$ interneurons described in this report. This indicates that an important component of conditioning-associated plasticity in the network responsible for generating the CR is in the type I interneurons. The present results may explain how CS-elicited enhancement of the generator potential, CS-elicited enhancement of complex PSP amplitude of interneurons, and facilitation of monosynaptic PSPs in interneurons of conditioned animals produces behavioral inhibition. Inhibition of light-elicited ciliary

$$
\begin{array}{lllllllllllllll}
L & E & A & R & N & I & N & G & \mathcal{Z} & M & E & M & O & R & Y \\
\text { www.learnmem.org } & & &
\end{array}
$$


A

\section{Conditioned}

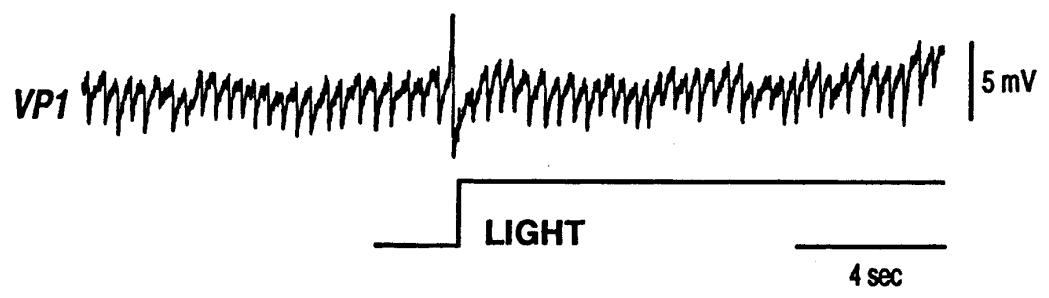

B Pseudorandom

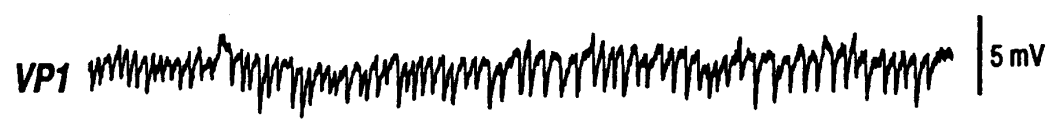

LIGHT

C

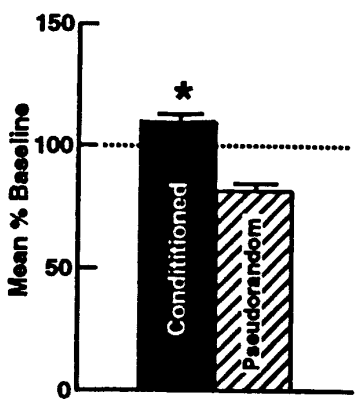

Figure 6 Light-elicited changes in VP1 IPSP frequency in conditioned animals and pseudorandom controls. (A) Example of a light-elicited increase in VP1 IPSPs relative to baseline from a conditioned preparation. $(B)$ Example of a light-elicited decrease in VP1 IPSPS relative to baseline from a pseudorandom control preparation. ( $C$ ) Group data depicting the mean percent change from baseline during light-evoked (1 $\mathrm{min})$ IPSP frequency for conditioned animals $(n=12)$ and pseudorandom controls $(n=11)(* P<.001)$.

locomotion may be caused by conditioning-dependent increases in IPSP frequency in VP1 elicited by enhanced depolarization and increased spike activity of $\mathrm{I}_{e}$ interneurons, resulting in an increase in VP1 IPSP frequency and a decrease in the tonic spike activity of VP1 pedal neurons.

In a number of invertebrates, interneurons have been identified as sites of plasticity. A network of interneurons has been shown to contribute to olfactory learning and olfactory discrimination in Limax (Kleinfeld et al. 1994; Gelperin and Flores 1997; Ermentrout et al. 2001). Modifications in interneurons in the feeding circuit of Lymnaea have been identified in conditioned animals (Benjamin et al. 2000). In Aplysia, interneurons have been proposed as sites of plasticity in habituation and sensitization (Cleary et al. 1995). A correlate of food avoidance learning in Pleurobranchaea is a reduction in EPSP amplitude in CCD interneurons of the feeding circuit (Kovac et al. 1986). In addition, intrinsic changes in excitability of leech $\mathrm{S}$ cells occur with nonassociative learning of the shortening reflex (Burrell et al. 2001), and Retzius cells express a correlate of CS-US predictability (Sahley and Crow 1998).

Enhancement of excitability in cortex and hippocampus is a general characteristic of Pavlovian conditioning in mammals (Woody and Engel 1972; Woody et al. 1976; Disterhoft et al. 1986; Moyer et al. 1996; Thompson et al. 1996). A number of invertebrate preparations also exhibit enhanced excitability in identified neurons of conditioned animals (for review see Sahley and Crow 1998). Studies of Pavlovian conditioning of Hermissenda have identified several sites of plasticity in the CS pathway consisting of modifications in both excitability and synaptic efficacy (Crow and Alkon 1980; Farley and Alkon 1982; West et al. 1982; Frysztak and Crow 1993, 1994, 1997; Gandhi and Matzel 2000; Crow and Tian 2002b). Voltage-clamp experiments conducted on type B photoreceptors isolated by axotomy after conditioning showed that voltage $\left(\mathrm{I}_{\mathrm{A}}\right.$, $\left.\mathrm{I}_{\mathrm{Ca}}\right)$ and $\mathrm{Ca}^{2+}$-dependent $\left(\mathrm{I}_{\mathrm{K}, \mathrm{Ca}}\right)$ currents are reduced (Alkon et al. 1982, 1985; Collin et al. 1988). The net effect of modifications in the different extrinsic membrane conductances of sensory neurons (photoreceptors) could explain the CSelicited enhancement of the generator potential and CS-evoked increase in spike activity of the sensory neurons from conditioned animals. These changes in excitability in conjunction with synaptic facilitation of the monosynaptic B-photoreceptor-type I interneuron PSP may explain the enhancement of complex PSPs in type $I_{e}$ and $I_{i}$ interneurons (Crow and Tian 2002b). The observation described in this report of an enhancement of excitability of type $I_{e}$ interneurons with conditioning is the first evidence for intrinsic changes in interneurons in Hermissenda produced by Pavlovian conditioning. Taken collectively, the plasticity in the various components of the CS pathway provides an explanation for light-elicited inhibition of ciliary locomotion in conditioned animals.

One of the characteristics of Pavlovian conditioning is the formation of a new response (CR) elicited by the CS after training. In Hermissenda the response evoked by the CS before conditioning is different from both the UR and CR. Since a new response, inhibition of locomotion and foot shortening (CRs), is elicited by the CS after training, condi-

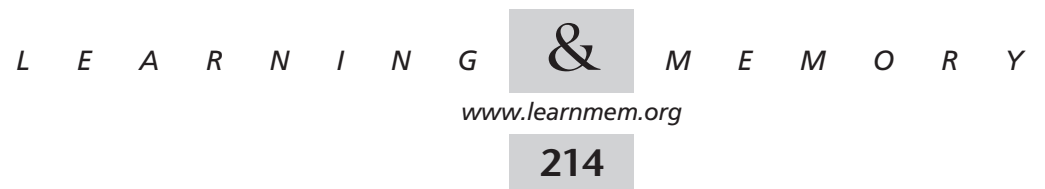


tioning in Hermissenda is not an example of reflex potentiation (e.g. Schreurs 1989). However, since the CS-elicits an increase in spike activity, synaptic facilitation, and an increased amplitude of complex PSPs in components of the CS pathway, it is not clear how such changes could be expressed in the inhibition of behavior. Interestingly, the present findings suggest that the balance of synaptic connections between type $I_{e}, I_{i}$ interneurons and VP1 pedal neurons are functionally modified by Pavlovian conditioning. Therefore, CS-evoked activation of type $I_{e}$ interneurons and inhibition of type $I_{i}$ interneurons produces a net inhibition of the tonic spike activity of cilliary activating VP1 pedal neurons normally excited by light.

\section{MATERIALS AND METHODS}

\section{Animals}

Adult Hermissenda crassicornis were used in the experiments The animals were obtained from Sea Life Supply, and maintained in closed artificial seawater aquaria at $14 \pm 1{ }^{\circ} \mathrm{C}$ on a 12-h light, 12 -h dark cycle. Behavioral training, testing and electrophysiological procedures were performed during the light phase of the light/dark cycle.

\section{Baseline Test of Phototactic Behavior}

The details of the conditioning procedure and methods for testing phototactic behavior have been described in detail in previous publications (Crow and Alkon 1978; Crow and Offenbach 1983) and will be described only briefly in this report. Animals were tested prior to training to determine baseline latencies to initiate locomotion in response to a test light. Animals that did not respond within a $20 \mathrm{~min}$ criterion period during the pretraining measurements were not used in the conditioning experiments. Previous research has shown that the increase in the time taken by the animals to locomote into a test light can be accounted for by an increase in the latency to initiate locomotion (Crow and Offenbach 1983). Animals were placed into glass tubes $228-\mathrm{mm}$ long filled with artificial seawater. A foam plug inserted through an opening confined the animal to one end of the tube. The tubes were attached by spring clips to a modified turntable enclosed in an incubator maintained at $15^{\circ} \mathrm{C}$. Animals were dark-adapted for $12 \mathrm{~min}$ prior to testing phototactic behavior. A light spot $\left(10^{-4}\right.$ watts $/ \mathrm{cm}^{2}$, white light) was projected onto the center of the turntable, illuminating a circular area $15-16 \mathrm{~cm}$ in diameter. The elapsed times to initiate locomotion in the presence of the test light were recorded when a Hermissenda moved between an infrared emitter and a phototransistor located at the starting end of each glass tube. When the infrared beam was interrupted, a free running digital clock was turned off and the time recorded for later data analysis.

\section{Conditioning Procedure}

Following baseline testing, animals were randomly assigned to the conditioned group or pseudorandom control group. The conditioning phase consisted of 50 trials of the $10 \mathrm{sec}$ CS (light) paired with the unconditioned stimulus (US; high speed rotation; mean ITI $=2.5 \mathrm{~min}$ ), presented each day for 2 consecutive days. The intensity of the CS was the same as the test light used to establish baseline responding for phototactic behavior during the pretest condition. The pseudorandom control group received a total of 100 trials of the CS and US (50 trials each day for 2 consecutive days), each programmed to occur randomly with respect to time and each other with the restriction that the CS and US could not overlap.

\section{Post-Acquisition Test}

All animals received behavioral testing identical to the pretraining (baseline) test measurement for phototaxis $24 \mathrm{~h}$ after the second conditioning session. Animals that did not initiate locomotion in the presence of the CS within $20 \mathrm{~min}$ during the posttest received a maximum latency score. Assessment of conditioning was determined by computing suppression ratios that compared posttraining phototactic behavior with pretraining test scores. The ratio is expressed as $(A / A+B)$ where $A$ represents pretraining scores and $B$ represents posttraining scores. Conditioned animals exhibited behavioral suppression that was similar in magnitude to previous reports (Crow and Alkon 1978; Crow and Offenbach 1983). After postacquisition testing all animals were coded so that the collection of electrophysiological data was conducted using completely blind experimental procedures.

\section{Intracellular Recordings}

Intracellular recordings from identified type I interneurons and VP1 pedal neurons were collected from isolated nervous systems. The type I interneurons were localized to a region of the cerebropleural ganglion as noted in previous publications (Akaike and Alkon 1980; Crow and Tian 2000, 2002a). Surgical desheathing of a small area of the cerebropleural and pedal ganglion was conducted to expose the cell bodies of type I interneurons and pedal neurons. Type I interneurons were identified based upon soma size, cell layer, location in the cerebropleural ganglion, and light-elicited complex PSPs as previously reported (Crow and Tian 2000, 2002a). Pedal neurons were identified by size, position along the anterior-ventral edge of the pedal ganglia, and electrophysiological responses to light and extrinsic current stimulation of pedal nerves and interneurons.

The partially desheathed circumesophageal nervous systems were pinned to a silicone elastomer (Sylgard; Dow Chemical) stage in a recording chamber filled with ASW of the following composition (mM): $460 \mathrm{NaCl}, 10 \mathrm{KCl}, 10 \mathrm{CaCl}_{2}, 55 \mathrm{MgCl}_{2}$, buffered with 10 mM HEPES and brought to $\mathrm{pH} 7.46$ with dilute $\mathrm{NaOH}$. The ASW in the recording chamber was monitored by a thermistor and held at $15 \pm 0.5^{\circ} \mathrm{C}$. CS illumination of the eyes was provided by a tungsten halogen incandescent lamp attached to a fiber optic bundle mounted underneath the recording chamber. For simultaneous recordings, identified pairs of type I interneurons and pedal neuron VP1 were impaled with microelectrodes filled with $4 \mathrm{~m} \mathrm{KAc}$ and connected to the two headstages of an Axoclamp 2A (Axon Instruments). Electrode resistances varied between 60 and $90 \mathrm{M} \Omega$. Digitized data were analyzed and plotted using Spike 2 Software (Cambridge Electronics Design). Spikes and PSPs evoked by the CS, and elicited by 1-min and 5-min presentations of light were collected from conditioned animals and pseudorandom controls. IPSPs recorded in VP1 were evoked by 2-sec and 5-sec extrinsic depolarizing current pulses applied to type $\mathrm{I}_{\mathrm{e}}$ interneurons. Baseline activity for spikes and IPSPs in VP1 pedal neurons was collected during the same time period immediately preceding light or current stimulation. Excitability of type $\mathrm{I}_{\mathrm{e}}$ interneurons was assessed with $0.1 \mathrm{nA}$, $0.2 \mathrm{nA}$, and $0.3 \mathrm{nA}$ depolarizing 2-sec extrinsic current pulses. Effects involving more than two groups were assessed with an ANOVA followed by posthoc comparisons (Tukey tests). Two group comparisons involved $t$-tests for independent groups.

\section{ACKNOWLEDGMENTS}

We thank Diana Parker for assistance with the manuscript. This research was supported by National Institutes of Health Grant MH58698 .

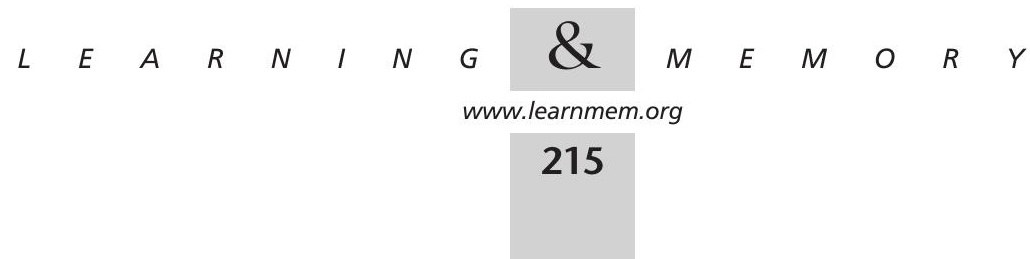


The publication costs of this article were defrayed in part by payment of page charges. This article must therefore be hereby marked "advertisement" in accordance with 18 USC section 1734 solely to indicate this fact.

\section{REFERENCES}

Akaike, T. and Alkon, D.L. 1980. Sensory convergence on central visual neurons in Hermissenda. J. Neurophysiol. 44: 501-513.

Alkon, D.L. 1973a. Neural organization of a molluscan visual system. $J$. Gen. Physiol. 61: 444-461.

Alkon, D.L. 1973b. Intersensory interactions in Hermissenda. J. Gen. Pbysiol. 62: 185-202.

Alkon, D.L. and Fuortes, M.G.F. 1972. Responses of photoreceptors in Hermissenda. J. Gen. Physiol. 60: 631-649.

Alkon, D.L., Akaike, T., and Harrigan, J. 1978. Interaction of chemosensory, visual and statocyst pathways in Hermissenda crassicornis. J. Gen. Physiol. 71: 177-194.

Alkon, D.L., Lederhendler, I., and Shoukimas, J.J. 1982. Primary changes of membrane currents during retention of associative learning. Science 215: 693-695.

Alkon, D.L., Sakakibara, M., Forman, R., Harrigan, J., Lederhendler, I., and Farley, J. 1985. Reduction of two voltage-dependent $\mathrm{K}^{+}$currents mediates retention of a learned association. Behav. Neurol. Biol. 44: 278-300.

Benjamin, P.R., Stanas, K., and Kemones, G. 2000. A systems approach to the cellular analysis of associative learning in the Lymnaea. Learn. Mem. 7: 124-131

Burrell, B.D., Sahley, C.L, and Muller, K.J. 2001. Nonassociative learning and serotonin induce similar bidirectional change in excitability of a neuron critical for learning in the medicinal leech. J. Neurosci. 24: 1401-1412

Cleary, L.J., Byrne, J.H., and Frost, W.N. 1995. Role of interneurons in defensive withdrawal reflexes in Aplysia. Learn. Mem. 2: 133-151.

Collin, C.C., Ikeno, H., Harrigan, J.F., Lederhendler, I., and Alkon, D.L. 1988. Sequential modifications of membrane currents with classical conditioning. Biophys. J. 54: 955-960.

Crow, T. and Alkon, D.L. 1978. Retention of an associative behavioral change in Hermissenda. Science 201: 1239-1241.

Crow, T. and Alkon, D.L. 1980. Associative behavioral modification in Hermissenda: Cellular correlates. Science 209: 412-414.

Crow, T. and Offenbach, N. 1983. Modification of the initiation of locomotion in Hermissenda: Behavioral analysis. Brain Res. 271: 301-310.

Crow, T. and Tian, L.-M. 2000. Monosynaptic connections between identified $\mathrm{A}$ and $\mathrm{B}$ photoreceptors and interneurons in Hermissenda: Evidence for labeled-lines. J. Neuropbysiol. 84: 367-375.

Crow, T. and Tian, L.-M. 2002a. Morphological characteristics and central projections of two types of interneurons in the visual pathway of Hermissenda. J. Neurophysiol. 87: 322-332.

Crow, T. and Tian, L.-M. 2002b. Facilitation of monosynaptic and complex PSPs in type I interneurons of conditioned Hermissenda. J. Neurosci. 22: $7818-7824$

Crow, T. and Tian, L.-M. 2003. Interneuronal projections to identified cilia-activating pedal neurons in Hermissenda. J. Neurophysiol. (in press)

Crow, T., Heldman, E., Hacopian, V., Enos, R., and Alkon, D.L. 1979 Ultrastructure of photoreceptors in the eye of Hermissenda labeled with intracellular injections of horseradish peroxidase. J. Neurocyt. 8: $181-195$

Disterhoft, J.F., Coulter, D.A., and Alkon, D.L. 1986. Conditioning-specific membrane changes of rabbit hippocampal neurons measured in vitro. Proc. Natl. Acad. Sci. 83: 2733-2737.

Ermentrout, B., Wang, J.W., Flores, J., and Gelperin, A. 2001. Model for olfactory discrimination and learning in Limax procerebrum incorporating oscillatory dynamics and wave propagation. $J$. Neuropbysiol. 85: 1444-1452.

Farley, J. and Alkon, D.L. 1982. Associative neural and behavioral change in Hermissenda: Consequences of nervous system orientation for light- and pairing-specificity. J. Neurophysiol. 48: 785-807.

Frysztak, R.J. and Crow, T. 1993. Differential expression of correlates of classical conditioning in identified medial and lateral type A photoreceptors of Hermissenda. J. Neurosci. 13: 2889-2897.

Frysztak, R.J, and Crow, T. 1994. Enhancement of type B and A photoreceptor inhibitory synaptic connections in conditioned Hermissenda. J. Neurosci. 14: 1245-1250.

Frysztak, R.J. and Crow, T. 1997. Synaptic enhancement and enhanced excitability in presynaptic and postsynaptic neurons in the conditioned stimulus pathway of Hermissenda. J. Neurosci. 17: 4426-4433.

Gandhi, C.L. and Matzel, L.D. 2000. Modulation of presynaptic action potential kinetics underlies synaptic facilitation of type $B$ photoreceptors after associative conditioning in Hermissenda. J. Neurosci. 20: 2022-2035.

Gelperin, A. and Flores, J. 1997. Vital staining from dye-coated microprobes identifies new olfactory interneurons for optical and electrical recording. J. Neurosci. Meth. 72: 97-108.

Goh, Y. and Alkon, D.L. 1984. Sensory, interneuronal, and motor interactions within Hermissenda visual pathway. J. Neurophysiol. 52: 156-169.

Goh, Y., Lederhendler, J., and Alkon, D.L. 1985. Input and output changes of an identified neural pathway are correlated with associative learning in Hermissenda. J. Neurosci. 5: 536-543

Hodgson, T.M. and Crow, T. 1991. Characterization of four light responsive putative motor neurons in the pedal ganglia of Hermissenda crassicornis. Brain Res. 557: 255-264.

Hodgson, T.M. and Crow, T. 1992. Cellular correlates of classical conditioning in identified light responsive pedal neurons of Hermissenda crassicornis. Brain Res. 570: 267-271.

Jerussi, T.P. and Alkon, D.L. 1981. Ocular and extraocular responses of identifiable neurons in pedal ganglia of Hermissenda crassicornis. J. Neurophysiol. 46: 659-671.

Kleinfeld, D., Delaney, K.R., Fee, M.S., Flores, J.A., Tank, D.W., and Gelperin, A. 1994. Dynamics of propagating waves in the olfactory network of a terrestrial mollusk: An electrical and optical study. $J$. Neurophysiol. 72: 1402-1419.

Kovac, M.P., Matera, E.M., Volk, P.J., and Davis, W.J. 1986. Food avoidance learning is accompanied by synaptic attenuation in identified interneurons controlling feeding behavior in Pleurobranchaea. J. Neurophysiol. 56: 891-905.

Lederhendler, I.I., Gart, S., and Alkon, D.L. 1986. Classical conditioning of Hermissenda: Origin of a new response. J. Neurosci. 6: 1325-1331.

Moyer, J.R., Thompson, L.T., and Disterhoft, J.F. 1996. Trace eyeblink conditioning increases CA1 excitability in a transient and learning-specific manner. J. Neurosci. 16: 5536-5546.

Richards, W.G. and Farley, J. 1987. Motor correlates of phototaxis and associative learning. Brain Res. Bull. 19: 174-189.

Sahley, C.L. and Crow, T. 1998. Invertebrate learning: Current perspectives. In Learning and Memory (eds. J.L. Martinez Jr., and R.P. Kesner), pp. 177-209. Academic Press, New York, NY.

Schreurs, B.G. 1989. Classical conditioning of model systems: A behavioral review. Psychobiol. 17: 145-155.

Thompson, L.T., Moyer, J.R., and Disterhoft, J.F. 1996. Transient changes in excitability of rabbit CA3 neurons with a time-course appropriate to support memory consolidation. J. Neurophysiol. 70: 1210-1220.

West, A., Barnes, E.S., and Alkon, D.L. 1982. Primary changes of voltage responses during retention of associative learning. J. Neurophysiol. 48: $1243-1255$.

Woody, C.D. and Engel Jr., J. 1972. Changes in unit activity and thresholds to electrical stimulation of coronal-pericruciate cortex of cat with classical conditioning of different facial movements. J. Neurophysiol. 35: 230-241.

Woody, C.D., Knispel, J.D., Crow, T.J., and Black-Cleworth, P.A. 1976 Activity and excitability to electrical current of cortical auditory receptive neurons of awake cats as affected by stimulus association. $J$. Neurophysiol. 39: 1045-1061.

Received January 6, 2003; accepted in revised form March 19, 2003

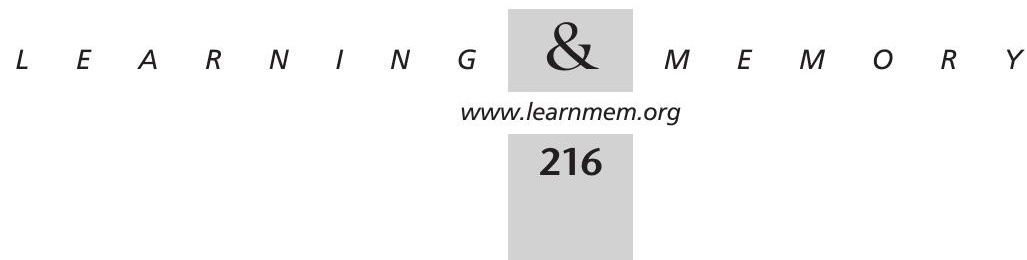




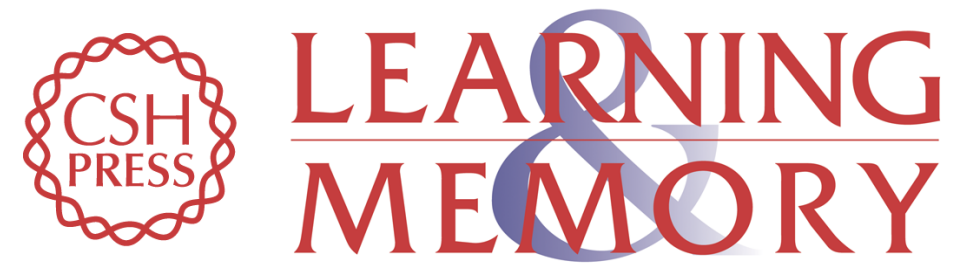

\section{Neural Correlates of Pavlovian Conditioning in Components of the Neural Network Supporting Ciliary Locomotion in Hermissenda}

Terry Crow and Lian-Ming Tian

Learn. Mem. 2003, 10:

Access the most recent version at doi:10.1101//m.58603

References This article cites 37 articles, 15 of which can be accessed free at: http://learnmem.cshlp.org/content/10/3/209.full.html\#ref-list-1

License

Email Alerting

Receive free email alerts when new articles cite this article - sign up in the box at the Service top right corner of the article or click here. 